\title{
Simultaneous lidar observations of temperatures and waves in the polar middle atmosphere on the east and west side of the Scandinavian mountains: a case study on 19/20 January 2003
}

\author{
U. Blum ${ }^{1}$, K. H. Fricke ${ }^{1}$, G. Baumgarten ${ }^{2}$, and A. Schöch ${ }^{2}$ \\ ${ }^{1}$ Physikalisches Institut der Universität Bonn, D-53115 Bonn, Germany \\ ${ }^{2}$ Leibniz-Institut für Atmosphärenphysik e.V., D-18225 Kühlungsborn, Germany
}

Received: 9 January 2004 - Published in Atmos. Chem. Phys. Discuss.: 11 February 2004

Revised: 20 May 2004 - Accepted: 25 May 2004 - Published: 3 June 2004

\begin{abstract}
Atmospheric gravity waves have been the subject of intense research for several decades because of their extensive effects on the atmospheric circulation and the temperature structure. The U. Bonn lidar at the Esrange and the ALOMAR RMR lidar at the Andøya Rocket Range are located in northern Scandinavia $250 \mathrm{~km}$ apart on the east and west side of the Scandinavian mountain ridge. During January and February 2003 both lidar systems conducted measurements and retrieved atmospheric temperatures. On 19/20 January 2003 simultaneous measurements for more than $7 \mathrm{~h}$ were possible. Although during most of the campaign time the atmosphere was not transparent for the propagation of orographically induced gravity waves, they were nevertheless observed at both lidar stations with considerable amplitudes during these simultaneous measurements. And while the source of the observed waves cannot be determined unambiguously, the observations show many characteristics of orographically excited gravity waves. The wave patterns at ALOMAR show a random distribution with time whereas at the Esrange a persistency in the wave patterns is observable. This persistency can also be found in the distribution of the most powerful vertical wavelengths. The mode values are both at about $5 \mathrm{~km}$ vertical wavelength, however the distributions are quite different, narrow at the Esrange with values from $\lambda_{z}=2-6 \mathrm{~km}$ and broad at ALOMAR, covering $\lambda_{z}=1-12 \mathrm{~km}$ vertical wavelength. In particular the difference between the observations at ALOMAR and at the Esrange can be understood by different orographic conditions while the propagation conditions were quite similar. At both stations the waves deposit energy in the atmosphere with increasing altitude, which leads to a decrease of the observed gravity wave potential energy density with altitude. The meteorological situation during these measurements was different from common winter situations. The ground winds
\end{abstract}

Correspondence to: U. Blum

(blum@physik.uni-bonn.de) were mostly northerlies, changed in the upper troposphere and lower stratosphere to westerlies and returned to northerlies in the middle stratosphere.

\section{Introduction}

It is well established that atmospheric waves of different scales and types play a key role in driving the global circulation and thus influencing the temperature structure of the atmosphere (e.g. Lindzen, 1981; Holton, 1983; Fritts and Alexander, 2003). The formation of polar stratospheric clouds (PSCs) in the northern hemisphere is often driven by gravity wave induced cooling (Carslaw et al., 1998) when the synoptic scale temperatures are a few Kelvin above the formation temperature of PSCs. These waves can be excited orographically by surface obstacles and the Scandinavian mountain ridge is a major source (Størmer, 1929; Volkert and Intes, 1992). Several international field campaigns and model studies have already investigated the influence of the Scandinavian mountain ridge on gravity waves and PSC formation (Dörnbrack and Leutbecher, 2001; Dörnbrack et al., 2002). The vertical propagation of gravity waves is influenced by the background wind field. In particular, a turning of the wind direction with altitude by $180^{\circ}$ will lead to critical level filtering for all upward propagating gravity waves. For stationary gravity waves, which have zero phase speed relative to the ground, a critical level will occur where the background wind direction is perpendicular to the waves propagation direction (cf. Whiteway and Duck, 1996). It was shown by Dunkerton and Butchart (1984) that the wind patterns accompanying a sudden warming act to reduce, but not to eliminate, the propagation of quasi-stationary gravity waves to the mesosphere. Strong disturbances of the horizontal wind field occur during major stratospheric warmings (Scherhag, 1952; Matsuno, 1971) which are regularly observed in the polar winter stratosphere (Labitzke and Naujokat, 2000). 
The U. Bonn lidar at the Esrange and the ALOMAR RMR lidar at the Andøya Rocket Range are both well equipped to retrieve atmospheric temperature profiles from about $30 \mathrm{~km}$ to roughly $80 \mathrm{~km}$ altitude with a time resolution of $1 \mathrm{~h}$. These profiles frequently show temperature disturbances which can be identified as atmospheric internal gravity waves.

In January and February 2003 a field campaign took place to investigate the impact of the Scandinavian mountain ridge on atmospheric gravity waves. The U. Bonn lidar and the ALOMAR RMR lidar performed measurements whenever permitted by the weather conditions, to maximise the chance for simultaneous measurements. Due to different meteorological situations at both stations - affected by the Scandinavian mountain ridge - the tropospheric cloud coverage differs extremely, thus opportunities for simultaneous measurements are rare. Nevertheless a total of nine simultaneous measurements were obtained during the campaign. Although one minor and one major stratospheric warming occurred at the beginning of January as well as another minor warming in the middle of February leading to critical level filtering in the lower stratosphere, on several days wave signatures were observed in the middle stratosphere at both lidar stations. On 19/20 January 2003 a simultaneous data set of more than $7 \mathrm{~h}$ duration was obtained. These data and the accompanying wave analysis are presented here. First we will present the lidar data used. Then the adopted analysis method is described. The meteorological background situation is described in Sect. 4 based mainly on ECMWF analyses. The observations of 19/20 January 2003 are presented and discussed in Sects. 5 and 6. Finally the results are summarised.

\section{Lidar data}

The U. Bonn lidar is located at the Esrange $\left(68^{\circ} \mathrm{N}, 21^{\circ} \mathrm{E}\right)$ near the Swedish city of Kiruna. The ALOMAR RMR lidar is located next to the Andøya Rocket Range $\left(69^{\circ} \mathrm{N}, 16^{\circ} \mathrm{E}\right)$ about $250 \mathrm{~km}$ to the north-west of the Esrange. Between both stations the Scandinavian mountain ridge is a major source for the excitation of mountain waves. The Scandinavian mountains turn to west-east direction right north of the Esrange. Thus there are mountains which can act as an excitation obstacle for gravity waves to the west and the north of the Esrange. During polar winter eastward winds regularly dominate the mean horizontal flow in the troposphere and stratosphere. However, during our measurements the meteorological situation was markedly different as explained in detail in Sect. 4.

The U. Bonn lidar and the ALOMAR RMR lidar both use a pulsed Nd:YAG solid state laser as light source. The backscattered light from the atmosphere is collected by telescope systems, detected by photomultipliers, and recorded by counting electronics (Müller et al., 1997; von Zahn et al., 2000). The elapsed time between the emission of a light pulse and the detection of the echo determines the scatter- ing altitude. In the aerosol free part of the atmosphere (i.e. typically above $30 \mathrm{~km}$ altitude) the backscattered light is proportional to the molecular number density. Assuming hydrostatic equilibrium, the integration of the range corrected lidar net signal yields the temperature profile. At the upper end of the profile (i.e. at about $75-85 \mathrm{~km}$ ) a seed temperature has to be estimated, which we take from the MSISE90 (Hedin, 1991) or CIRA86 (Fleming et al., 1990) models, respectively. The altitude resolution of both lidar systems is $150 \mathrm{~m}$, however, smoothing of the raw data before temperature calculation reduces this altitude resolution to about one kilometer. The time resolution is determined by the integration time of the lidar data. Longer integration times result in temperature profiles reaching higher altitudes having higher precision but losing time resolution. This is a well known trade-off in all lidar systems.

Here lidar data were integrated for $1 \mathrm{~h}$ with a shift in the starting point of $15 \mathrm{~min}$ resulting in a number of individual, though not fully independent profiles for each measurement night. The integration for the complete night results in a mean temperature profile, which reaches higher up and shows less wave structure than the individual profiles.

During the campaign in January/February 2003, the U. Bonn lidar conducted 29 measurement runs, lasting from less than $1 \mathrm{~h}$ up to more than $61 \mathrm{~h}$ with continuous data. During this period the ALOMAR RMR lidar performed 16 measurement runs with durations from about $1 \mathrm{~h}$ up to $26 \mathrm{~h}$. In total there were nine simultaneous measurement runs lasting from half an hour up to more than $7 \mathrm{~h}$. During the night of $19 / 20$ January the U. Bonn lidar started with measurements on 19 January at 14:21 UT, ending on 20 January at 10:18 UT, whereas the ALOMAR RMR lidar measurements lasted from 19 January, 19:28 UT to 20 January, 02:40 UT. Thus we have $7.2 \mathrm{~h}$ of simultaneous measurements during this night which will be discussed here.

\section{Analysis method}

The first step in data processing is to subtract the night mean temperature profile from the individual profiles to obtain the residuals, which are then identified as the wave induced variations. For the wave analysis we use the power spectrum and the gravity wave potential energy density of the observed waves as well as the maximum vertical wavelength, which can propagate through the atmosphere.

From the residual profiles we calculate the Fourier transform, which results in the vertical wavelength spectra. From these spectra we derive the dominant vertical wavelengths.

Time series of the residual profiles can be used to calculate the gravity wave potential energy density per volume $\left(G W P E D_{\mathrm{vol}}\right)$, given by

$G W P E D_{\mathrm{vol}}(z)=\frac{1}{2} \frac{g^{2}(z)}{N^{2}(z)} \overline{\left(\frac{\Delta T(z)}{T(z)}\right)^{2}} n(z) \bar{m}$. 
This quantity consists essentially of the time mean of the squared relative temperature variation $\overline{(\Delta T(z) / \overline{T(z)})^{2}}$, where $\Delta T(z)$ is the temperature perturbation and $\overline{T(z)}$ is the night mean temperature profile. This quantity is further multiplied by a stability factor $g^{2}(z) / N^{2}(z)$, where $g(z)$ is the acceleration due to gravity and $N(z)$ the Brunt-Väisälä frequency. The symbol $n(z)$ stands for the atmospheric number density which is taken from the lidar measurement. The range-corrected net signal is directly proportional to the atmospheric number density. The calibration factor is found through comparison with ECMWF analyses. Finally $\bar{m}$ is the mean molecular mass of the atmosphere. The GWPED $D_{\mathrm{vol}}$ is a measure of the potential energy available in a gravity wave and can be used to estimate energy dissipation with altitude. In case of energy conservation in an ascending wave, the value of the $G W P E D_{\mathrm{vol}}$ is constant along the ray path. In case of stationary gravity waves the wave energy propagates vertically. This is along the line of sight of the lidar.

To estimate the transparency of the atmosphere for stationary gravity waves we use ECMWF T106 analysis data on 28 pressure levels from ground up to the lower mesosphere. Using the dispersion relation for medium frequency waves $(N \gg \hat{\omega} \gg f$, where $\hat{\omega}$ is the intrinsic frequency of the waves and $f$ the inertial frequency or Coriolis parameter), the vertical wavenumber is

$k_{z}=\frac{2 \pi}{\lambda_{\max }}=\frac{N}{\left|\overline{u_{h}}-c_{p h}\right|}$

(e.g. Fritts, 1984). $\overline{u_{h}}$ is the mean horizontal wind in the direction of wave propagation and $c_{p h}$ the horizontal phase velocity of the wave. Equation (2) allows us to calculate the maximum vertical wavelength $\lambda_{\max }$ which can propagate through the atmosphere. Critical levels imply that $\lambda_{\max }$ approaches zero. For vertically ascending waves the horizontal phase velocity relative to the ground is $c_{p h}=0 \mathrm{~m} / \mathrm{s}$. Thus the maximum vertical wavelength $\lambda_{\max }$ can be written as

$\lambda_{\max }(z)=\overline{\left|u(z)_{h}\right|} P_{B}(z)$

where $P_{B}=2 \pi / N$ is the Brunt-Väisälä period. Due to the fact that the propagation direction of the wave is not determinable by the single location measurements of the lidar stations, we will assume and discuss two selected, orthogonal states in Sects. 5 and 6: 1) The intrinsic phase speed is purely zonally and 2) the intrinsic phase speed is purely meridionally.

\section{Meteorological background}

The temperature profiles retrieved by the two lidar systems during the whole campaign period provide an overview of the mean atmospheric temperature structure above northern Scandinavia in early 2003 (Fig. 1).

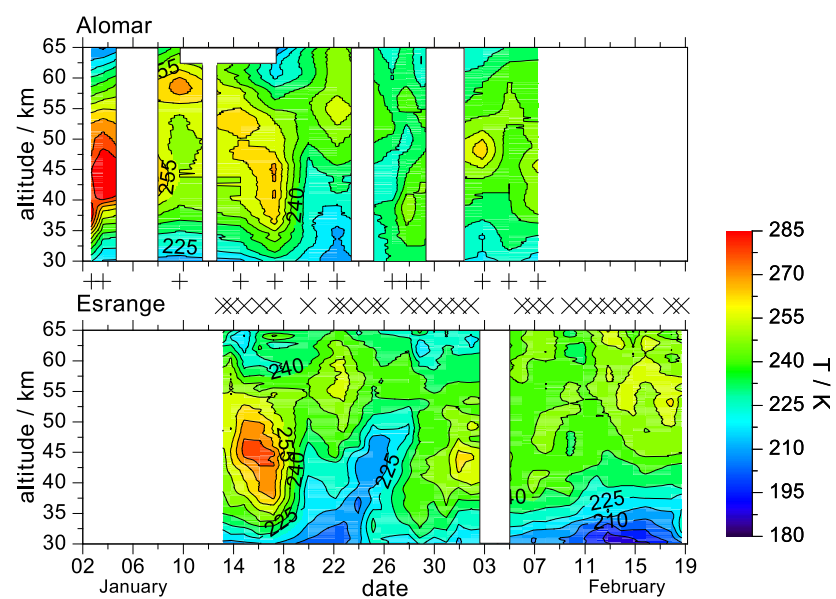

Fig. 1. Evolution of the nightly mean temperatures as observed by the ALOMAR RMR lidar in Norway (upper row) and the U. Bonn lidar at the Esrange in Sweden (lower row) for January and February 2003. The abscissa shows the date of January/February 2003, the ordinate the altitude in kilometers, and the color code the temperature in Kelvin. Measurement times are marked by "+"-signs for ALOMAR data and " $x$ "-signs for Esrange data.

Due to the alternating good measurement conditions at both lidar stations we have a nearly complete temperature coverage for the time period January/February 2003. These nightly mean temperature profiles show a similar structure on a coarse scale on both sides of the mountains but the details reveal differences. The ALOMAR RMR lidar was operating from 2 January onward and could observe a first stratospheric warming during 2 and 3 January. A second warming on 15-17 January was observed by both lidar instruments. Although the temperatures observed with the ALOMAR RMR lidar show higher values during the first warming than during the second, the hemispheric view asserts that the first warming was a minor warming, whereas the second event was a major stratospheric warming, including a wind reversal (Naujokat and Grunow, 2003) and consequently a split up of the vortex. In the beginning of the lidar campaign the ALOMAR RMR lidar measured stratopause temperatures of up to $309 \mathrm{~K}$ at an altitude of about $43 \mathrm{~km}$. High stratopause temperatures of $280 \mathrm{~K}$ were observed at about $45 \mathrm{~km}$ altitude by both lidars during 15-17 January. Following this warming unusually cold temperatures in the altitude range of $30-50 \mathrm{~km}$ were observed during an eight days period. In the beginning of February during a six days period (5-11 February) the atmosphere was almost isothermal from about $40-65 \mathrm{~km}$ altitude which is typical for the final recovery stage of major warmings observed early in January (Labitzke, 1971).

The wind pattern leads to critical level filtering during almost the entire campaign period. Figure 2 shows the calculated critical levels, using horizontal winds from ECMWF T106 analyses for January and February 2003 at Kiruna. For 


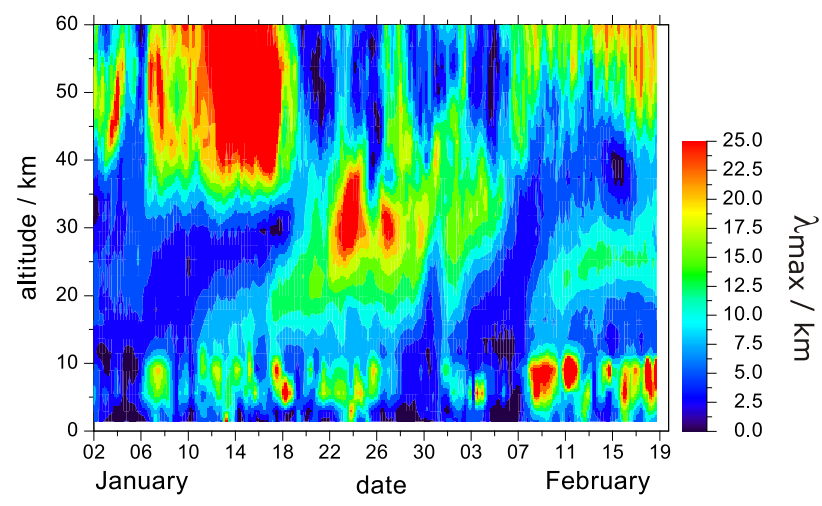

Fig. 2. Critical level calculation for Esrange with ECMWF T106 data. The abscissa shows the date on January/February 2003, the ordinate the altitude and the color code the maximum vertical wavelength $\lambda_{\max }$, which can penetrate through the respective atmospheric level. Dark blue areas are critical levels which inhibit vertical propagation of internal gravity waves.

a coarse overview the use of the horizontal wind is sufficient, whereas for the detailed discussion we will distinguish between zonal and meridional propagation directions.

Plotted is the maximum vertical wavelength $\lambda_{\max }$ which can penetrate through the atmosphere. Red regions mean large values for $\lambda_{\max }$, i.e. the atmosphere is transparent, whereas dark blue and black regions indicate critical levels which inhibit propagation of (orographically induced) gravity waves. Due to the reduced vertical resolution of about $1 \mathrm{~km}$ both lidars cannot detect gravity waves with vertical wavelengths shorter than $2 \mathrm{~km}$. The atmosphere was transparent for stationary waves during the stratospheric warmings in the first weeks of January above $35 \mathrm{~km}$ altitude, but waves were not able to penetrate through the lower and middle stratosphere up to this altitude. This situation changed directly after the major warming and led to a more transparent middle and lower stratosphere. However, critical levels occurred around the stratopause altitude. From the beginning of February onwards, the middle and lower stratosphere were again dominated by critical levels, thus mountain waves were not able to ascend from the ground into the stratosphere and mesosphere.

The long simultaneous measurement on 19/20 January 2003 by both lidar systems took place exactly during the period during which critical level filtering decreased in the lower atmosphere and the chance increased for mountain waves to propagate up to the stratopause.

Figure 3 shows the ECMWF T511 analysis data for 19 January 18:00 UT and 20 January 00:00 UT at three different pressure levels $(850 \mathrm{hPa}, 70 \mathrm{hPa}$, and $7 \mathrm{hPa})$. Plotted are the horizontal winds and geopotential heights. Additionally, weak wind divergences are indicated by red and blue lines. These divergences are often associated with the existence of inertial gravity waves (Plougonven and Teitelbaum, 2003).

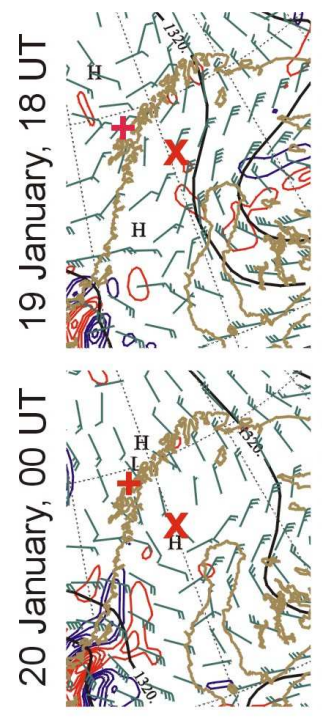

$850 \mathrm{hPa}$

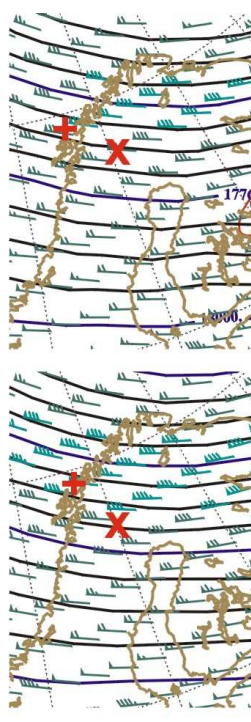

$70 \mathrm{hPa}$
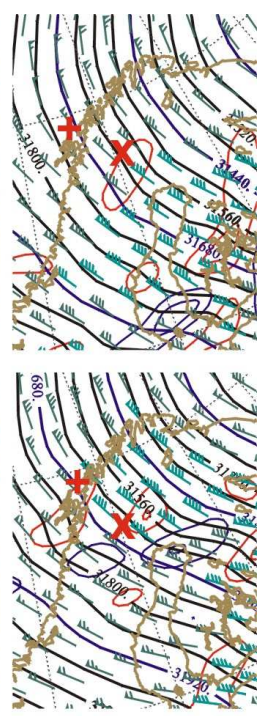

$7 \mathrm{hPa}$
Fig. 3. ECMWF T511 analysis data for 19 January 2003, 18:00 UT (upper row) and 20 January 2003, 00:00 UT (lower row) for three different pressure levels $850 \mathrm{hPa}$ (left column, $\sim 1.3 \mathrm{~km}$ ), $70 \mathrm{hPa}$ (middle column, $\sim 17.8 \mathrm{~km}$ ), and $7 \mathrm{hPa}$ (right column, $\sim 31.8 \mathrm{~km}$ ). Shown is the horizontal wind, geopotential height, and wind divergence. The stations are marked by a " $x$ "-sign for Esrange and a "+"'-sign for ALOMAR.

The meteorological situation during the measurement time was quite different from typical winter conditions. The pressure level of $850 \mathrm{hPa}$ corresponds to an altitude of about $1300 \mathrm{~m}$ which is about the altitude of the Scandinavian mountain ridge west and north of the Esrange. The winds near the ground $(850 \mathrm{hPa})$ are almost meridional, from the north at 19 January 18:00 UT and from the south six hours later. Further these winds are quite weak with $5-15 \mathrm{~m} / \mathrm{s}$. The wind system at higher altitudes is more constant with time. At $70 \mathrm{hPa}$ strong winds $(25-35 \mathrm{~m} / \mathrm{s})$ from the west dominate the flow. These westerlies cover most of the upper troposphere and lower stratosphere during the measurement time. With increasing altitude the wind direction turns back to northerlies. At $7 \mathrm{hPa}$, which is at about $31.8 \mathrm{~km}$ altitude, strong winds of about $15-20 \mathrm{~m} / \mathrm{s}$ blow from the north.

\section{Observations on 19/20 January 2003}

Figure 4 shows the individual temperature profiles for the night 19/20 January 2003, measured by the ALOMAR RMR lidar (left plot) and the U. Bonn lidar (right plot), respectively, during the simultaneous measurements. Temperature profiles from 19 January are plotted in red, those from 20 January in blue. Strong wave activity is found in all individual profiles on both stations covering the entire observed altitude range from $30-65 \mathrm{~km}$. Temperature variances are up to $10 \mathrm{~K}$. While the observed wave structure changes all the time above 

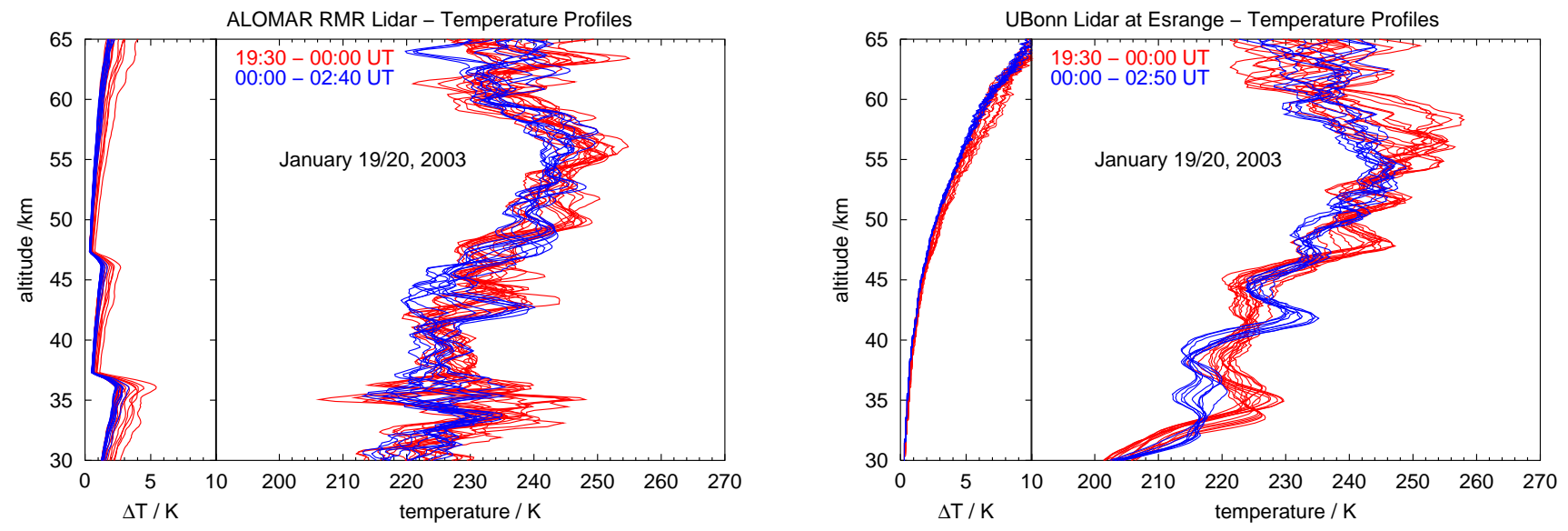

Fig. 4. Temperature profiles for 19/20 January 2003 measured by the ALOMAR RMR lidar (left plot) and the U. Bonn lidar (right plot). Shown are temperature profiles of $1 \mathrm{~h}$ integration time. The starting points of the integrations are shifted by $15 \mathrm{~min}$. The left part of each plot presents the temperature errors for each individual profile.
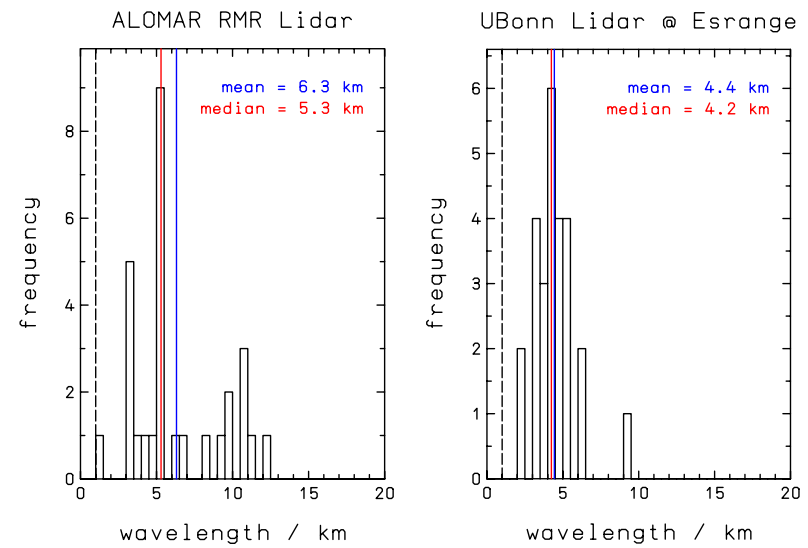

Fig. 5. Distribution of dominant vertical wavelengths at ALOMAR (left panel) and the Esrange (right panel) during the measurement night 19/20 January 2003. The abscissa gives the dominant vertical wavelength in $\mathrm{km}$ and the ordinate the absolute occurence rate of the respective wavelength. The mean and median values of the distribution are also given.

ALOMAR, the Esrange data show only two distinct profile types. Around midnight the wave system above the Esrange changes which can be seen most clearly around $35 \mathrm{~km}$, $43 \mathrm{~km}$, and $48 \mathrm{~km}$ altitude, where the temperature variation shows a phase jump leading to a change in temperature of about $15 \mathrm{~K}$.

For all profiles we calculated spectra of the vertical wavelength $\lambda_{z}$. Figure 5 shows the distribution of the dominant vertical wavelengths of the individual spectra.

The histograms show two different distribution patterns. The mean value for the distribution at ALOMAR is $6.3 \mathrm{~km}$ and hence much larger than the mean at the Esrange of $4.4 \mathrm{~km}$. The difference between median and mean is much smaller for the Esrange data than for the ALOMAR data

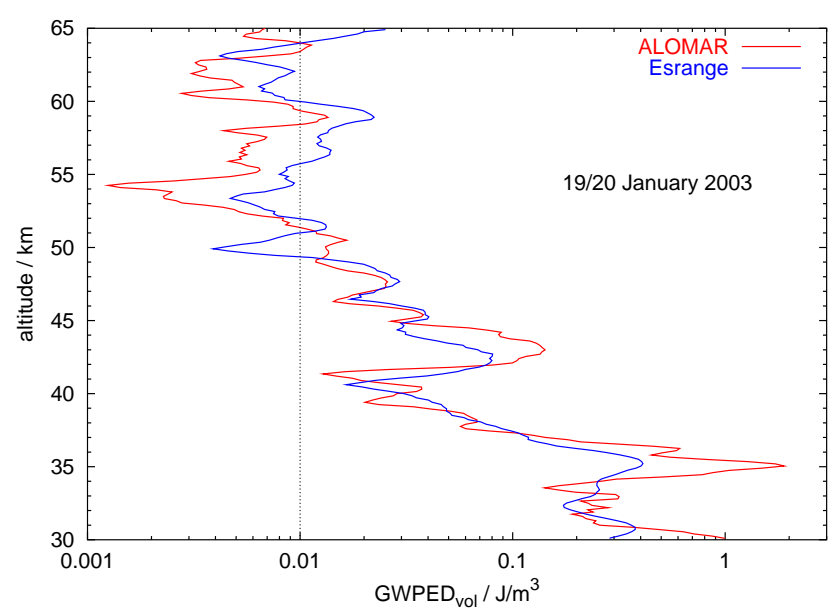

Fig. 6. Gravity wave potential energy density measured at ALOMAR and at the Esrange. ALOMAR data are shown in red, the blue line represents the Esrange profile.

which is consistent with the different shapes of the distributions. Whereas the distribution at ALOMAR ranges from $\lambda_{z}=1-12 \mathrm{~km}$, that at the Esrange covers mainly values from $\lambda_{z}=2-6 \mathrm{~km}$. In fact the distribution at ALOMAR seems to comprise two different distributions, one dominant with a mean value at about $5 \mathrm{~km}$ and a second, less pronounced around $10 \mathrm{~km}$ vertical wavelength. Thus the wave spectrum at the Esrange is more narrow than at ALOMAR which indicates less variability in the waves above the Esrange. The prominent persistency of the wave pattern in the Esrange data seen in Fig. 5 in comparison to the ALOMAR data is thus also represented in the spectra.

From the residual profiles we derived the gravity wave potential energy density per volume, using Eq. (1). Figure 6 shows the potential energy density measured at both stations. 

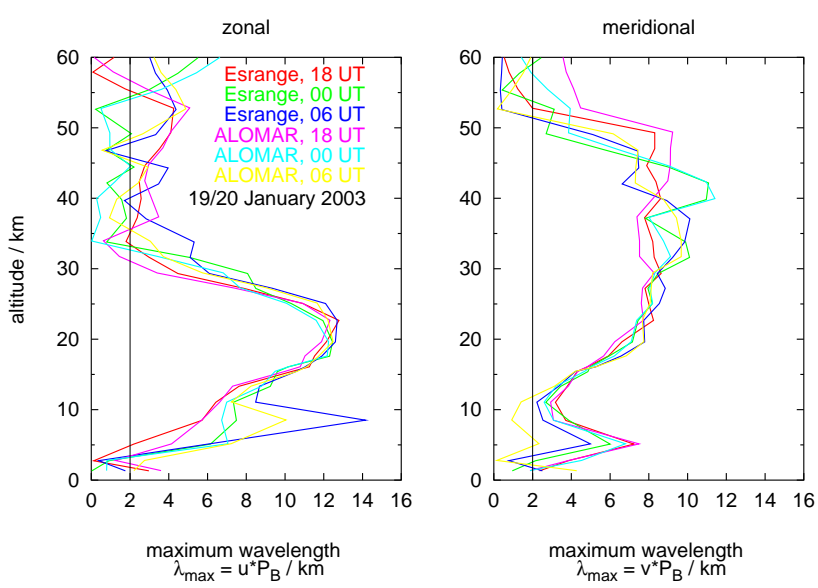

Fig. 7. Atmospheric transparency for mountain waves derived from ECMWF T106 analyses for 19/20 January 2003. Shown are the maximum vertical wavelengths $\lambda_{\max }$ which can penetrate through the atmosphere for purely zonally (left plot) and purely meridionally propagating gravity waves (right plot). Vertical lines at $2 \mathrm{~km}$ mark the minimum wavelength observable by the lidar instruments.

The coarse structure is quite similar at both sides of the mountains up to an altitude of $50 \mathrm{~km}$. The $G W P E D_{\mathrm{vol}} \mathrm{de}-$ creases from about $0.5 \mathrm{~J} / \mathrm{m}^{3}$ near $30 \mathrm{~km}$ by a factor of 50 to values of $0.01 \mathrm{~J} / \mathrm{m}^{3}$ near $50 \mathrm{~km}$ altitude. In the altitude range above $50 \mathrm{~km}$ the mean potential energy density stays constant on both sides of the mountains, with about $0.01 \mathrm{~J} / \mathrm{m}^{3}$ at the Esrange and $0.005 \mathrm{~J} / \mathrm{m}^{3}$ at ALOMAR. The measurements indicate that the observed waves deposit energy with increasing altitude in the $30-50 \mathrm{~km}$ altitude region.

Figure 7 shows the maximum vertical wavelengths $\lambda_{\max }$ (see Eq. 3) for waves which can propagate through the atmosphere derived from ECMWF T106 wind data, for assumptions of purely zonal (left plot) and meridional (right plot) phase propagation directions, respectively.

ECMWF T106 analyses are available every $6 \mathrm{~h}$ of which we use data for 19 January, 18:00 UT, 20 January, 00:00 UT and 06:00 UT. According to the ECMWF analyses the atmospheric conditions were quite similar at both stations. With the present instrumental setup and the data analysis the lidars cannot observe gravity waves with vertical wavelengths shorter than $2 \mathrm{~km}$.

In the lower troposphere the wind direction and speed created critical level filtering in the $2-3 \mathrm{~km}$ altitude range for zonally propagating waves. The maximum vertical wavelength which can propagate for meridionally propagating gravity waves increases in the lower troposphere from $\lambda_{\max } \approx 1-2 \mathrm{~km}$. Higher up in the troposphere at about $10 \mathrm{~km}$ altitude a critical level for meridionally propagating waves evolved above ALOMAR an 20 January, 06:00 UT; however throughout the stratosphere meridionally propagating waves were able to propagate during the observation time. Maximum vertical wavelengths of $\lambda_{\max } \approx 10 \mathrm{~km}$, which is larger

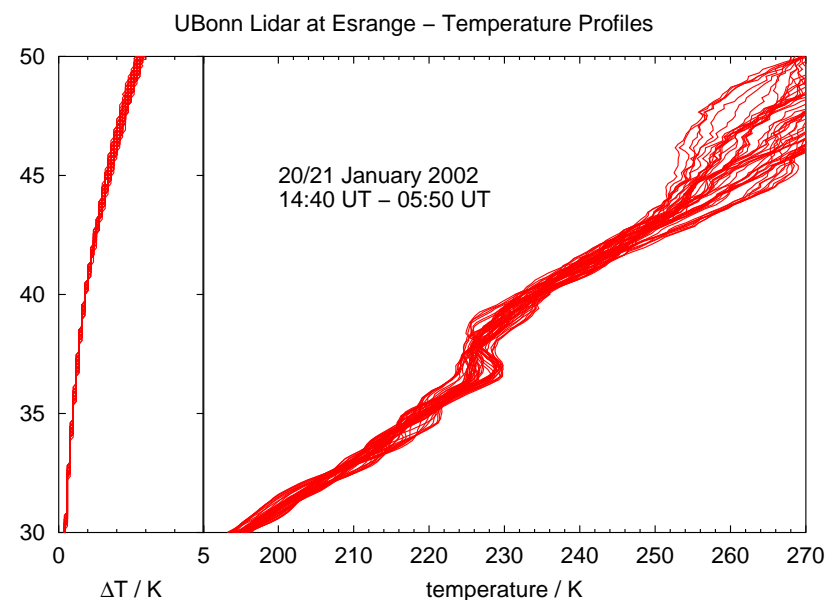

Fig. 8. Temperature profiles for $20 / 21$ January 2002 measured by the U. Bonn lidar. Compared to the data in Fig. 4 waves are missing. See Fig. 4 for information of the data type.

than the observed mean vertical wavelength, indicate this. Due to the modification of the vertical wavelength by the background wind, shorter wavelengths can propagate from the ground in the stratosphere and then modify to larger wavelengths as found in the lidar data. Different from the meridionally propagating waves, zonally propagating gravity waves met a critical level already at about $35 \mathrm{~km}$ altitude. Higher up the maximum allowed propagable vertical wavelength stayed low with values of about $0-4 \mathrm{~km}$.

\section{Discussion}

On 19/20 January 2003 the ALOMAR RMR lidar and the U. Bonn lidar both observed wave signatures in the temperature profiles up to $65 \mathrm{~km}$ altitude. Obviously during the measurements of this case study critical level filtering did not occur in the troposphere and lower stratosphere. To illustrate the drastic effects of critical level filtering Fig. 8 shows temperature profiles measured with the U. Bonn lidar at the Esrange one year previously on 20/21 January 2002. No wave patterns are observable, the profiles are very smooth, although the ground winds were similar to those of 19/20 January 2003 with about $5 \mathrm{~m} / \mathrm{s}$ from the north-east. The lack of clear wave signatures in the temperature profiles is caused by critical level filtering of gravity waves just at the lowest altitude of the measurements as Fig. 9 shows. A wind turn of $180^{\circ}$ prevents all gravity waves from propagating further upward. Such a turn-around in the horizontal wind existed between 30 and $40 \mathrm{~km}$ altitude on 20/21 January 2002 but not on 19/20 January 2003.

During 19/20 January 2003 the GWPE $D_{\mathrm{vol}}$ was very similar on both stations, showing a strong decrease in potential energy density from 30 to $50 \mathrm{~km}$ altitude. Thus the propagation conditions in the upper stratosphere and lower mesosphere were similar on the east and west side of the 

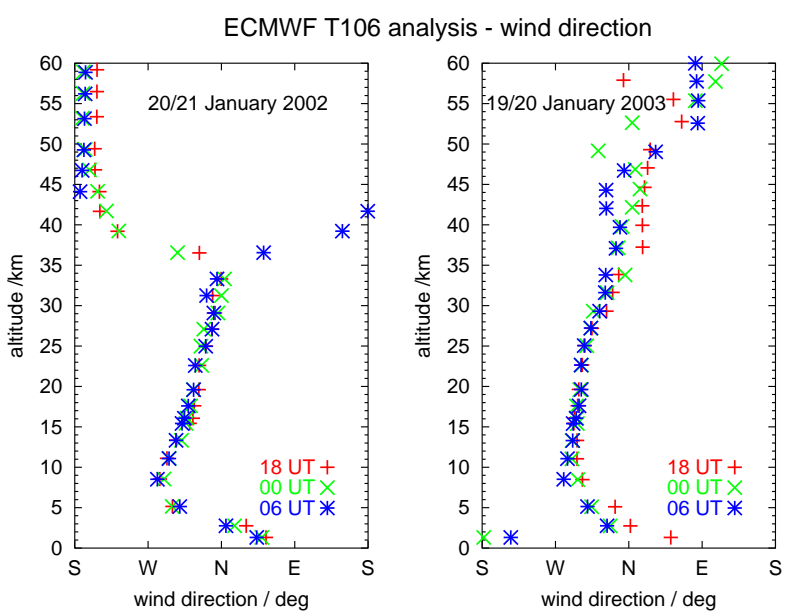

Fig. 9. Direction of horizontal wind taken from ECMWF above the Esrange for the two different days 20/21 January 2002 (left plot) and 19/20 January 2003 (right plot) at different times.

mountains, leading to this decrease in wave energy above $30 \mathrm{~km}$ altitude. The observed decrease of the GWPED $D_{\mathrm{vol}}$ does not agree with the maximum vertical wavelength $\lambda_{\max }$, derived from ECMWF data for zonally propagating gravity waves, however it is compatible with meridionally propagating gravity waves. Whereas the zonally propagating gravity waves must die out above $35 \mathrm{~km}$, meridionally propagating gravity waves can reach altitudes of about $50 \mathrm{~km}$ before $\lambda_{\max }$ decreases. Thus the direction of phase propagation must be close to meridional. Analogous to the GW PE $D_{\mathrm{vol}}$ the maximum vertical wavelength $\lambda_{\max }$ must decrease. Filtering of waves with longer wavelengths reduces the total amount of potential energy transported by the gravity waves.

The observations are consistent with stationary gravity waves. However, due to the limitation of the data-set to altitudes above $30 \mathrm{~km}$ the source of the waves cannot be determined directly. But by complementing the lidar observations with ECMWF analyses it is possible to constrain the number of plausible wave sources.

The above analysis of the lidar data indicates that the wave phase propagates meridionally. This is consistent with the ECMWF analyses which indicate winds from the north at $3 \mathrm{~km}$ altitude and below leading to mostly meridionally propagating gravity waves (cf. Pavelin and Whiteway, 2002). Actually the wind turning by about $90^{\circ}$ with altitude may influence upward propagating waves, however, a complete critical level filtering does not occur. The observed differences among both lidar stations are consistent with orographically induced gravity waves. Northerlies excite gravity waves on the Scandinavian mountains north of the Esrange, however north of ALOMAR there is only ocean. This will result in different wave patterns above both stations. Around midnight we find a turn in the ground-level wind of about $140^{\circ}$. The data of the ALOMAR wind profiler (ALWIN VHF radar at Andøya) show that this turn occurs at about 23:30 UT on
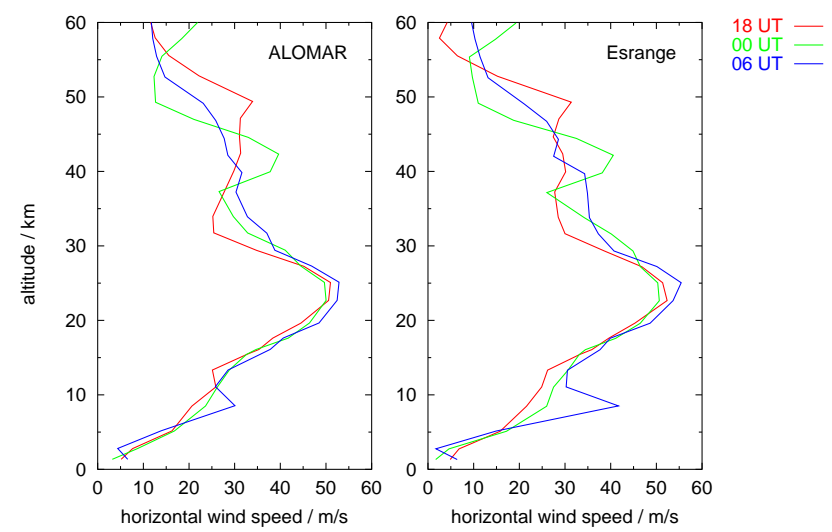

Fig. 10. ECMWF T106 data for 19/20 January 2003. Shown is the mean horizontal wind speed $\bar{u}$. The left panel contains the data for ALOMAR, the right one those for Esrange. Data for $19 \mathrm{Jan}-$ uary, 18:00 UT (red line), 20 January, 00:00 UT (green line) and for 20 January, 06:00 UT (blue line) are shown.

19 January 2003 above ALOMAR. This wind turn results in different excitation conditions for orographically induced gravity waves, because the orography south of the two stations is quite different to the orography north of the stations. At the Esrange we can see the influence of this turn directly in the temperature profiles by the change in the wave pattern.

Another possible source of the observed waves might be in the atmosphere itself. The wind velocities and directions of the horizontal wind at different altitudes show large variations. These wind-differences lead to strong shear stress which might also be a source of wave activity. However, this does not explain the large differences in the observations at both stations. The velocity and direction of the horizontal wind in the free atmosphere is similar above both stations. Thus, if the waves were excited in the atmosphere, one would expect very similar observations.

Figure 10 shows the ECMWF mean horizontal wind speeds $\bar{u}$ for ALOMAR (left panel) and Esrange (right panel) at three different times covering the observation period of both lidars.

The wind profiles are rather constant during the measurement time of the lidars. Only the last wind profiles of $20 \mathrm{Jan}-$ uary, 06:00 UT show initial stages of a tropospheric jet at about $8 \mathrm{~km}$ altitude. This jet is more pronounced at Esrange with a horizontal wind speed of about $45 \mathrm{~m} / \mathrm{s}$ than at ALOMAR with $30 \mathrm{~m} / \mathrm{s}$. The tropospheric jet might cause a change in the propagation conditions for atmospheric gravity waves above the Esrange or act as additional wave source resulting in the observed change of the individual temperature profiles around midnight.

\section{Summary}

On 19/20 January 2003 we obtained more than $7 \mathrm{~h}$ of simultaneous lidar measurements using the U. Bonn lidar at 
the Esrange and the ALOMAR RMR lidar at the Andøya Rocket Range, $250 \mathrm{~km}$ apart on the east and west side of the Scandinavian mountains during unusual meteorological conditions. Gravity wave signatures were detected in the temperature profiles of both stations. The ground winds were dominated by northerlies as well as the winds in the upper stratosphere. But in the upper troposphere and lower stratosphere the dominant wind direction was eastward. Around midnight the ground-level winds turned by about $140^{\circ}$ which led to different excitation conditions resulting in a change in the wave pattern.

The gravity wave potential energy density per volume shows very similar characteristics on both sides of the mountains while the observed temperature profiles as well as the distributions of the dominant vertical wavelengths reveal large differences. The ECMWF wind data indicate that there were no critical levels for meridionally propagating mountain waves up to the stratopause although a wind turn of about $90^{\circ}$ with altitude is observable in the upper troposphere and lower stratosphere. The random-like distribution of wave pattern with time at ALOMAR indicates variable excitation conditions whereas the persistent wave structure at the Esrange suggests a constant excitation of mountain waves. This is consistent with the local orography where there are the Scandinavian mountains reaching altitudes of about $1000 \mathrm{~m}$ north of the Esrange while there is only ocean north of ALOMAR.

Acknowledgements. We thank the staffs of the Esrange and the Andøya Rocket Range for their always quick and uncomplicated support during the measurement campaigns. We wish to thank P. Hoffmann for providing data of the ALOMAR MST-radar ALWIN. Further we are indebted to A. Dörnbrack for an additional, comprehensive set of meteorological data. The measurements at ALOMAR were supported by the "Access to the ALOMAR research infrastructure" project of the European Union. The measurements at the Esrange were funded by the Envisat Validation project granted by the DLR Erdbeobachtung FKZ 50 EE 0009. Finally we like to thank the NILU for providing the ECMWF T106 analysis data.

\section{Edited by: M. Dameris}

\section{References}

Carslaw, K. S., Wirth, M., Tsias, A., Luo, B. P., Dörnbrack, A., Leutbecher, M., Volkert, H., Renger, W., Bacmeister, J. T., Reimer, E., and Peter, T.: Increased stratospheric ozone depletion due to mountain-induced atmospheric waves, Nature, 391, 675-678, 1998.

Dörnbrack, A. and Leutbecher, M.: Relevance of mountain waves for the formation of polar stratospheric clouds of Scandinavia: A 20 years climatology, J. Geophys. Res., 106, 1583-1593, 2001.

Dörnbrack, A., Birner, T., Fix, A., Flentje, H., Meister, A., Schmid, H., Browell, E. V., and Mahoney, M. J.: Evidence for inertia gravity waves forming polar stratospheric clouds over Scandinavia, J. Geophys. Res., 107, doi:10.1029/2001JD000452, 2002.

Dunkerton, T. J. and Butchart, N.: Propagation and selective transmission of internal gravity waves in a sudden warming, J. Atmos. Sci., 41, 1443-1460, 1984.
Fleming, E. L., Chandra, S., Barnett, J. J., and Corney, M.: Zonal mean temperature, pressure, zonal wind, and geopotential height as function of latitude, Adv. Space Res., 10, 12, 11-59, 1990.

Fritts, D. C.: Gravity wave saturation in the middle atmosphere: A review of theory and observations, Rev. Geophys., 22, 3, 275308, 1984.

Fritts, D. C. and Alexander, M. J.: Gravity wave dynamics and effects in the middle atmosphere, Rev. Geophys., 41, 1, 1003, doi:10.1029/2001RG000106, 2003.

Hedin, A. E.: Neutral atmosphere empirical model from the surface to the lower exosphere MSISE90, J. Geophys. Res., 96, 11591172, 1991.

Holton, J. R.: The influence of gravity wave breaking on the general circulation of the middle atmosphere, J. Atmos. Sci., 40, $2497-$ 2507, 1983.

Labitzke, K.: Temperature changes in the mesosphere and stratosphere connected with circulation changes in winter, J. Atmos. Sci., 29, 756-766, 1971.

Labitzke, K. and Naujokat, B.: The lower Arctic stratosphere in winter since 1952, SPARC Newsletter, 15, 11-14, 2000.

Lindzen, R. S.: Turbulence and stress owing to gravity wave and tidal breakdown, J. Geophys. Res., 86, 9707-9714, 1981.

Matsuno, T.: A dynamical model of the stratospheric sudden warming, J. Atmos. Sci., 28, 1479-1494, 1971.

Müller, K.-P., Baumgarten, G., Siebert, J., and Fricke, K. H.: The new lidar facility at Esrange, Kiruna, Proceedings of the 13th ESA symposium on European Rocket and Ballon Programmes and Related Research, Öland, May 1997, Sweden, ESA-SP-397, 129-134, 1997.

Naujokat, B. and Grunow, K.: The stratospheric Arctic winter 2002/03: Balloon flight planning by trajectory calculations, Proceedings of the 16th ESA symposium on European Rocket and Ballon Programmes and Related Research, St. Gallen, May 2003, Switzerland, ESA-SP-530, 421-425, 2003.

Pavelin, E. and Whiteway, J. A.: Gravity wave interactions around the jet stream, Geophys. Res. Lett., 29, doi:10.1029/2002GL015783, 2002.

Plougonven, R. and Teitelbaum, H.: Comparison of largescale intertia-gravity wave as seen in the ECMWF analyses and from radiosondes, Geophys. Res. Lett., 30, doi:10.1029/2003GL017716, 2003.

Scherhag, R.: Die explosionsartige Stratosphärenerwärmung des Spätwinters 1951/1952, Ber. Deut. Wetterdienst, 6, 51-62, 1952.

Størmer, C.: Remarkable clouds at high altitudes, Nature, 123, 260 261, 1929.

Volkert, H. and Intes, D.: Orographically forced stratospheric waves over northern Scandinavia, Geophys. Res. Lett., 19, 1205-1208, 1992.

von Zahn, U., von Cossart, G., Fiedler, J., Fricke, K. H., Nelke, G., Baumgarten, G., Rees, D., Hauchecorne, A., and Adolfsen, K.: The ALOMAR Rayleigh/Mie/Raman lidar: Objectives, configuration, and performance, Ann. Geophys., 18, 815-833, 2000.

Whiteway, J. A. and Duck, T. J.: Evidence for critical level filtering of atmospheric gravity waves, Geophys. Res. Lett., 23, 145-148, 1996. 